\title{
Examining Software Intellectual Property Rights
}

\author{
Ehsan Sargolzaei \\ Computer Engineering Department, Faculty of Engineering \\ University of Zabol \\ Zabol, Iran
}

\author{
Fateme Keikha \\ Computer Engineering Department, Faculty of Engineering \\ University of Zabol \\ Zabol, Iran
}

\begin{abstract}
Intellectual property rights (IPR) of computer software is the right to assign the software to its creator, not limited to time and space, and non-transferable. Proving IPR of the creators of computer software requires a rigorous review of the ways in which these rights may be violated. The present study was conducted by comparing two populations in Iran with the aim of identifying the level of familiarity and observance of software IPR: 1) 96 software engineers member of IEEE Association and 2) 386 students randomly. Results are analyzed by SPSS software and the validity of the results is verified using T-test. By comparing the results, it was concluded that the first population significantly observed these cases more. Then a model was presented for protecting software IPR so that the challenges are reduced. This research is the completion of our previous work that was discussed as a future work.
\end{abstract}

Keywords-Software intellectual property rights (IPR); software piracy; copyright; patent

\section{INTRODUCTION}

Since 1970, ethics in software engineering has been trying to define ethical boundaries in computer technology. The attempt to elaborate ethical boundaries in software engineering has created explicit rules. This question arises for software engineers whether a particular act is ethical or not.

Under the IPR law of computer software creators, both in the form of an invention and in the form of a copyrighted work, legal support is provided for software. A small percentage of software in the world is Software Invention. Currently, most software is available in copyright. The importance of paying attention to software infrastructure is when businesses are now virtual and software-based. Thus, any weakness in software protection will be accompanied by the weakening and lack of development of these businesses, which, besides manufacturers, will also deprive consumers of their benefits.

The weakness in software support directly affects corporate profits and software sales decreases legally. Business Software Alliance reports these losses annually. Assessments presented based on private data from BSA group such as Microsoft and Intel indicates that this includes both software and hardware. However, the weakness in software support is far more likely to affect not only companies but also has long-term effects on the economy. If copyright are not perceived, the motivation for innovation that makes software newer and more efficient reduces [1].

However, discerning why population participates in this illegitimate acting increase the success of corporate or state measures. Considering this and to better understand what causes misuse of software, this article first examines these cases in the population, analyzes and compares them, and then classifies the factors relevant to the subject. In addition, a model to protect IPR of the software will be suggested. It determines how each of these factors affects IPR of the software. By doing so, we hope to provide a perspective helping corporations and governments plan better policies and practices to deal with this subject.

In the following, Section 2 shows related works. Section 3 details the objectives of this work, while Section 4 determines the measurement, sampling and data collection. The methods of analysis and analysis of achieved results are provided in Section 5. The effective factors in software piracy are given in Section 6, the conclusion is given in Section 7 and finally, we discuss future research of this article in Section 8.

\section{RELATED WORKS}

Software piracy damages software producers, creates unfair competition for companies, and leads customers to many security risks, including malware, security breaches, and loss of information [2].

In [3], many analytical techniques have been proposed regarding software development to detect software piracy. Software badge is a unique feature that can be used to identify the application. If in another program exactly the same sign is used, it is considered as a copy.

The Internet Business Patent supports a conceptual and software business model and does not require a physical implementation as a requisite for a traditional patent. The US courtroom has destroyed all barriers to software patents. These slow changes to extend the domain of software patents have reduced the productiveness of software copyright from a practical standpoint [4].

However many researches have studied software inventions, some have centralized on the economic aspect of copyrighted work. In [5], copyright law has been reviewed from an economic point of view.

In [6], the economic role of software patents, the use of software patents and stock market information in the duration from 1980 to 1999 were examined and it was shown that software patent court decisions had a negative impact on software products, and software industry does not profit from such resolves. As well as, [7] shows the indirect results for the implementation of US software, the acquisition of whose ownership of software patents was sponsored by venture capital firms. 


\section{SIGNIFICANCE AND OBJECTIVESASE}

In this research, we have tried to examine the level of familiarity with IPR of software and its observance, and how much IPR is tangible and familiar to population has been analyzed. Considering that the violation of software IPR is increasing, it is essential to analyze this reason to provide solutions to stop them. Our purpose in this study is to inspect the ethical challenges of the intellectual property of software and, based on the results, present feasible solutions for betterment of the situation, and finally present a model for protecting software IPR.

\section{Methodology}

\section{A. Measurement}

The tool for measuring variables and indicators in this research is the questionnaire. Also SPSS software is used to analyze data. The questionnaire is designed so that all observation of software IPR can be considered. Using the Likert scale [8], one can assign score to each of these questions and finally rate their questions and indices. The final score of the questions and indices is also calculated by averaging each one [9]. Now, with this assessment way it is possible to compute the indices received by the combination of different questions by means of averaging the results. Table 1 presents the challenges presented in this study.

TABLE I. The CHALLENGES USED IN THIS STUdy

\begin{tabular}{|l|l|l|}
\hline Ethical issues & $\begin{array}{l}\text { Number of } \\
\text { questions }\end{array}$ & Questions \\
\hline violation of software IPR (Copyright) & 11 & $1-11$ \\
\hline violation of software IPR (Trademarks) & 1 & 12 \\
\hline violation of software IPR (Trade Secrets) & 2 & 13,14 \\
\hline violation of software IPR (Patent) & 2 & 15,16 \\
\hline Other issues of violation of software IPR & 3 & $17-19$ \\
\hline
\end{tabular}

\section{B. Sampling and Data Collection}

The statistical population of this study contains two populations in Iran 1) 96 software engineer's member of IEEE Association and 2) 386 students randomly. Participation in responding the questionnaire is done voluntarily and absolutely anonymous.

\section{DATA ANALYSIS AND RESULT}

\section{A. Methods of Analysis}

The reliability of the questionnaire is measured by using Cronbach's alpha [10] coefficient. The Cronbach's alpha value of this study questionnaire is 0.706 which shows the acceptable reliability of this questionnaire.

The validity of the questionnaire is measured by using Bartlett Test of Sphericity [11] and $\mathrm{KMO}^{1}$ index [12] which is shown in Table 2.

\section{TABLE II. KMO AND BARTLETT'S TEST}

\begin{tabular}{|l|l|}
\hline Kaiser - Meyer- Olkin measures of sampling adequacy & $\mathbf{0 . 7 1 2}$ \\
\hline Bartlett's test of sphericity & \\
\hline Approx. chi- square & 358.312 \\
\hline Significance & 0.001 \\
\hline
\end{tabular}

\footnotetext{
${ }^{1}$ Kaiser-Meyer-Olkin
}

In this study, Bartlett Test of Sphericity is significant at a significance level of 0.05 because significance $\mathrm{P}<0.05$ and also the KMO value is desirable. Therefore, the questionnaire is Valid.

\section{B. Analysis of Achieved Results}

In this study, T-test [13] was used to examine the accuracy of the results. Table 3 sums up the results regarding the respondents' attitudes towards the ethical orientations to issues of software IPR in the population of the members of the IEEE Association.

In Table 3, descriptive statistics, including mean scores and standard deviations (SDs) for each statement, are given. The overall mean for the 19 statements is 3.13 , which is above the midpoint (3), thereby indicating a moderate level of awareness in protecting software IPR among the respondents. The highest mean (3.90) is for statement 1: "I do not intentionally use software that has been illegally obtained or kept". The standard deviation for this statement is 1.22 . Statement 16: "I do not give my thoughts and ideas for software design to anyone else" has the second highest mean, at 3.87, and a standard deviation of 1.06. Statement 10: "I do not offer the software produced with the participation of others exclusively" has the third highest mean, at 3.61, and a standard deviation of 1.32. Statements 2, 7 and 4 report the lowest means, respectively. Statement 2, with a mean of 2.07 and a standard deviation of 1.23, reads: "I buy the software I need legally". The second lowest mean is for statement 7 , which has a mean of 2.18 and a standard deviation of 1.18, it reads: "I deal seriously with people who use the software illegally". The third lowest mean is for statement 4, which has a mean of 2.28 and a standard deviation of 1.43 , it reads: "I advise friends and relatives to use the software legally."'. For Indicator of Copyright, different attitudes are indicated by the respondents' feedback on statements 1-11. The mean for the 11 statements is 2.99 and a standard deviation of 1.21 , which is under the midpoint (3), thereby indicating at the bottom level of awareness in protecting software IPR among the respondents. Therefore, for this Indicator high levels of concern are reported. They show the highest concern in statement 2: "I buy the software I need legally", followed by statement 7: "I deal seriously with people who use the software illegally'. Low levels of concern are reported for statement 1: "I do not intentionally use software that has been illegally obtained or kept", followed by statement 10: "I do not offer the software produced with the participation of others exclusively". For Indicator of Trademarks moderate levels of concern are reported (with a mean of 3.22 and a standard deviation of 1.42 ), statement 12 , with a mean of 3.22 and a standard deviation of 1.42, reads: "I do not use the title and badge of software for my software', For Indicator of Trade Secrets Low levels of concern are reported (with a mean of 3.53 and a standard deviation of 1.30), Statement 13, with a mean of 3.59 and a standard deviation of 1.27, reads: "I help my colleagues understand the working standards, methods to keep confidential information and general security considerations." and Statement 14, with a mean of 3.47 and a standard deviation of 1.34, reads: "I keep confidential information in my work environment that is kept in accordance with the rules" For Indicator of Patent Low moderate of concern are reported (with 
a mean of 3.28 and a standard deviation of 1.03), Low levels of concern are reported for Statement 16, with a mean of 3.87 and a standard deviation of 1.06, reads: "I do not give my thoughts and ideas for software design to anyone else" and They show the highest concern in Statement 15, with a mean of 2.69 and a standard deviation of 1.08 , reads: "I do not use the thought of others to produce software in my own name".

TABLE III. ETHICAL ORIENTATIONS TO ISSUES OF SOFTWARE IPR IN THE POPULATION OF THE MEMBERS OF THE IEEE ASSOCIATION

\begin{tabular}{|c|c|c|c|c|c|c|c|c|}
\hline No & Questions & Mean & SD & $\mathbf{S A}$ & $\mathbf{A}$ & $\mathbf{I}$ & $\mathbf{D}$ & SDi \\
\hline 1 & I do not intentionally use software that has been illegally obtained or kept. & 3.90 & 1.22 & 39.6 & 34.37 & 7.29 & 13.54 & 5.21 \\
\hline 2 & I buy the software I need legally. & 2.07 & 1.23 & 4.1 & 11.46 & 19.79 & 16.67 & 47.92 \\
\hline 3 & I do not give anyone the software I paid for on request. & 2.71 & 1.22 & 10.42 & 15.62 & 25 & 32.29 & 16.67 \\
\hline 4 & I advise friends and relatives to use the software legally. & 2.28 & 1.43 & 9.37 & 15.62 & 16.67 & 10.42 & 47.92 \\
\hline 5 & I do not trust software that is illegally produced. & 3.31 & 1.28 & 25 & 16.67 & 31.25 & 17.71 & 9.37 \\
\hline 6 & I remind people who are not aware of illegal use of software. & 3.11 & 1.07 & 10.42 & 22.92 & 43.75 & 13.54 & 9.37 \\
\hline 7 & I deal seriously with people who use the software illegally. & 2.18 & 1.18 & 4.1 & 11.46 & 19.79 & 27.08 & 37.50 \\
\hline 8 & I do not make publicly available software I have bought legally. & 3.43 & 1.33 & 22.92 & 35.42 & 16.67 & 11.46 & 13.54 \\
\hline 9 & I do not attribute to myself the software I have provided. & 3.22 & 1.32 & 20.83 & 25 & 21.87 & 19.79 & 13.54 \\
\hline 10 & I do not offer the software produced with the participation of others exclusively. & 3.61 & 1.32 & 34.37 & 25 & 16.67 & 15.62 & 8.33 \\
\hline 11 & I do not change software I have legally bought to create new software. & 3.08 & 1.37 & 21.87 & 15.62 & 28.12 & 17.71 & 16.67 \\
\hline 12 & I do not use the title and badge of software for my software. & 3.22 & 1.42 & 27.08 & 16.67 & 22.92 & 17.71 & 14.58 \\
\hline 13 & $\begin{array}{l}\text { I help my colleagues understand the working standards, methods to keep confidential } \\
\text { information and general security considerations. }\end{array}$ & 3.59 & 1.27 & 32.29 & 21.87 & 27.08 & 10.42 & 8.33 \\
\hline 14 & $\begin{array}{l}\text { I keep confidential information in my work environment that is kept in accordance } \\
\text { with the rules. }\end{array}$ & 3.47 & 1.34 & 32.29 & 17.71 & 23.96 & 16.67 & 9.37 \\
\hline 15 & I do not use the thought of others to produce software in my own name. & 2.69 & 1.08 & 4.1 & 15.62 & 42.71 & 19.79 & 17.71 \\
\hline 16 & I do not give my thoughts and ideas for software design to anyone else. & 3.87 & 1.06 & 36.42 & 26.04 & 28.12 & 7.29 & 2.08 \\
\hline 17 & $\begin{array}{l}\text { I accurately express the software specifications I work with and prevent false claims, } \\
\text { deception, and lies. }\end{array}$ & 3.36 & 1.10 & 18.75 & 20.83 & 45.83 & 7.29 & 7.29 \\
\hline 18 & $\begin{array}{l}\text { I fully validate the software work of the customers and refrain from illegal } \\
\text { validation. }\end{array}$ & 3.55 & 1.19 & 28.12 & 21.87 & 34.37 & 8.33 & 7.29 \\
\hline 19 & $\begin{array}{l}\text { I inform the customer about of the security weakness of the software I am working } \\
\text { on by the company I am working on. }\end{array}$ & 2.92 & 1.28 & 14.58 & 16.67 & 31.25 & 20.83 & 47.92 \\
\hline
\end{tabular}

SD: Standard deviation, SA: Strongly agree (\%), A: Agree (\%), I: Indifferent (\%), D: Disagree (\%), SDi: strongly disg. (\%)

TABLE IV. ETHICAL ORIENTATIONS To ISSUES OF SOFTWARE IPR IN THE POPULATION OF STUDENT

\begin{tabular}{|c|c|c|c|c|c|c|c|c|}
\hline No & Questions & Mean & SD & $\mathbf{S A}$ & $\mathbf{A}$ & $\mathbf{I}$ & $\mathbf{D}$ & SDi \\
\hline 1 & I do not intentionally use software that has been illegally obtained or kept. & 2.83 & 1.08 & 7.51 & 15.54 & 42.23 & 22.02 & 12.69 \\
\hline 2 & I buy the software I need legally. & 2.06 & 1.04 & 2.59 & 10.36 & 10.36 & 43.52 & 33.16 \\
\hline 3 & I do not give anyone the software I paid for on request. & 2.99 & 1.19 & 11.66 & 24.61 & 25.65 & 27.20 & 10.88 \\
\hline 4 & I advise friends and relatives to use the software legally. & 1.98 & 1.05 & 2.59 & 5.96 & 20.72 & 28.76 & 41.97 \\
\hline 5 & I do not trust software that is illegally produced. & 1.84 & 1.18 & 5.96 & 5.44 & 10.36 & 23.32 & 54.92 \\
\hline 6 & I remind people who are not aware of illegal use of software. & 1.95 & 1.25 & 7.77 & 5.70 & 11.92 & 23.32 & 51.29 \\
\hline 7 & I deal seriously with people who use the software illegally. & 1.37 & 0.91 & 1.04 & 5.44 & 5.18 & 4.92 & 83.16 \\
\hline 8 & I do not make publicly available software I have bought legally. & 2.77 & 1.10 & 5.44 & 24.35 & 22.54 & 36.79 & 10.88 \\
\hline 9 & I do not attribute to myself the software I have provided. & 3.19 & 1.15 & 14.77 & 22.54 & 40.41 & 11.66 & 10.62 \\
\hline 10 & I do not offer the software produced with the participation of others exclusively. & 2.04 & 1.37 & 13.21 & 2.84 & 7.77 & 26.94 & 49.22 \\
\hline 11 & I do not change software I have legally bought to create new software. & 1.35 & 0.86 & 2.07 & 2.07 & 5.70 & 8.55 & 81.61 \\
\hline 12 & I do not use the title and badge of software for my software. & 3.08 & 1.19 & 13.47 & 25.65 & 25.12 & 26.94 & 8.81 \\
\hline 13 & $\begin{array}{l}\text { I help my colleagues understand the working standards, methods to keep } \\
\text { confidential information and general security considerations. }\end{array}$ & 3.09 & 1.08 & 10.36 & 25.65 & 32.64 & 25.39 & 5.96 \\
\hline 14 & $\begin{array}{l}\text { I keep confidential information in my work environment that is kept in accordance } \\
\text { with the rules. }\end{array}$ & 2.93 & 1.12 & 11.14 & 13.99 & 44.82 & 17.36 & 12.69 \\
\hline 15 & I do not use the thought of others to produce software in my own name. & 1.46 & 0.99 & 3.37 & 3.63 & 5.44 & 10.88 & 76.68 \\
\hline 16 & I do not give my thoughts and ideas for software design to anyone else. & 3.27 & 1.19 & 19.95 & 19.95 & 36.79 & 14.51 & 8.81 \\
\hline 17 & $\begin{array}{l}\text { I accurately express the software specifications I work with and prevent false } \\
\text { claims, deception, and lies. }\end{array}$ & 3.39 & 1.16 & 23.06 & 19.17 & 39.12 & 11.66 & 6.99 \\
\hline 18 & $\begin{array}{l}\text { I fully validate the software work of the customers and refrain from illegal } \\
\text { validation. }\end{array}$ & 3.08 & 1.09 & 13.47 & 17.36 & 38.86 & 24.35 & 5.96 \\
\hline 19 & $\begin{array}{l}\text { I inform the customer about of the security weakness of the software I am working } \\
\text { on by the company I am working on. }\end{array}$ & 3.34 & 1.18 & 20.21 & 23.83 & 32.64 & 16.06 & 7.25 \\
\hline
\end{tabular}


Also, in Table 4 is presented the respondents' attitudes towards the ethical orientations to issues of software IPR in the population of student.

The overall mean for the 19 statements is 2.53 , which is under the midpoint (3), thereby indicating a low level of awareness in protecting software IPR among the respondents. The highest mean (3.39) is for statement 17. The standard deviation for this statement is 1.16. Statement 19 has the second highest mean, at 3.34, and a standard deviation of 1.18. Statement 16 has the third highest mean, at 3.27, and a standard deviation of 1.19 ; Statements 11, 7 and 15 report the lowest means, respectively; Statement 11, with a mean of 1.35 and a standard deviation of 0.86 . The second lowest mean is for statement 7 , which has a mean of 1.37 and a standard deviation of 0.91 . The third lowest mean is for statement 15 , which has a mean of 1.46 and a standard deviation of 0.99 . For Indicator of Copyright, The mean for the 11 statements (1-11) is 2.21 and a standard deviation of 1.03 , which is under the midpoint (3), thereby indicating at the bottom level of awareness in protecting software IPR among the respondents. Therefore, for this Indicator high levels of concern are reported. They show the highest concern in statement 11, followed by statement 7 . Low levels of concern are reported for statement 9. For Indicator of Trademarks moderate levels of concern are reported (with a mean of 3.08 and a standard deviation of 1.19. For Indicator of Trade Secrets high levels of concern are reported (with a mean of 3.01 and a standard deviation of 1.08), Low levels of concern are reported for Statement 13, with a mean of 3.09 and a standard deviation of 1.08 and They show the highest concern in Statement 14, with a mean of 2.93 and a standard deviation of 1.12. For Indicator of Patent Low of concern are reported (with a mean of 2.37 and a standard deviation of 0.99), low levels of concern are reported for Statement 16, with a mean of 3.27 and a standard deviation of 1.19 and They show the highest concern in Statement 15 , with a mean of 1.46 and a standard deviation of 0.99 .

For general, by comparing the results of population of the members of the IEEE Association and population of student, it was concluded that the members of the IEEE Association significantly observed these cases more.

\section{Checking the Achieved Results by using a Single-Sample T Test}

In Table 5, the analyses of each index (the mean score assigned to each index) for the IEEE members using a singlesample $t$ test are presented.

TABLE V. T TEST RESUlTS FOR THE INTELLECTUAL PROPERTy INDICES OF THE SOFTWARE (IEEE MEMBERS)

\begin{tabular}{|l|l|l|l|l|l|l|}
\hline Index & Mean & SD & D & Statistics T & significance P & CI \\
\hline violation of software IPR (Copyright) & 2.99 & 1.21 & -0.01 & -0.078 & 0.938 & 2.74 to 3.22 \\
\hline violation of software IPR (Trademarks) & 3.22 & 1.42 & 0.22 & 1.506 & 0.135 & 0.001 \\
\hline violation of software IPR (Trade Secrets) & 3.53 & 1.30 & 0.53 & 4.012 & 0.009 & 3.26 to 4.32 \\
\hline violation of software IPR (Patent) & 3.28 & 1.03 & 0.28 & 2.674 & 3.21 to 3.77 \\
\hline Other issues of violation of software IPR & 3.27 & 1.16 & 0.27 & 2.357 & 0.021 \\
\hline
\end{tabular}

For the Trade Secrets violation index, the mean value of the scores is 3.53 , which is 0.53 units up than the value of 3 , and the significance of the t-test at the $95 \%$ confidence level (Significance $\mathrm{P}<0.05$ ) indicates that the mean response of the individuals to the Trade Secrets violation component has a significant difference with the value of 3 and according to the $95 \%$ confidence interval, the mean response rate in the community with a $95 \%$ probability is within the range of $3.26-$ 4.32. Since the questionnaire options are defined so that the responses indicating the violation of the Trade Secrets of others tend to the large numbers (Smaller than 3) it is concluded that the violation of Trade Secrets is low among the members of the IEEE Association because firstly, the mean response of individuals is up than 3 (to the "Strongly agree " or nonviolation of Trade Secrets), and secondly, the mean value is significant compared to the number 3 (Significance $\mathrm{P}<0.05$ ) [9].

Similar to the abovementioned analysis and the data in Table 5, the violation of patent among the members of the IEEE Association is lower than the mean level.

For Copyright index, the mean value of the scores is 2.99 , which is 0.01 units less than the value of 3 , and the insignificance of the t-test at the 95\% confidence level (Significance $\mathrm{P} \geq 0.05$ ) indicates that the mean response of the individuals to the Copyright violation component has not a significant difference with the value of 3 and according to the 95\% confidence interval, the mean response rate in the community with a $95 \%$ probability is within the range of 2.74 3.22. it is concluded that The Copyright violation is average among the members of the IEEE Association because according to the above test the mean value is not significant in comparison with the number 3 (Significance $P \geq 0.05$ ). Similar to the abovementioned analysis and the data in Table 5, the violation of Trademarks is average among the members of the IEEE Association [9].

In Table 6, the analyses of each index for the population of student are presented.

Similar to the abovementioned analysis and the data in Table 6, for the Copyright violation index, the mean value of the scores is 2.21 , which is 0.79 units down than the value of 3 , the violation of Copyright is high among the members of student. In similar fashion:

- The violation of patent among the student is higher than the mean level.

- The Trade Secrets violation is higher than the mean among the student.

- The violation of Trademarks is average among the student. 
TABLE VI. T TEST RESULTS FOR THE INTELLECTUAL PROPERTy INDICES OF THE SOFTWARE (POPULATION OF STUDENT)

\begin{tabular}{|l|l|l|l|l|l|l|}
\hline Index & Mean & SD & D & Statistics T & Significance P & CI \\
\hline violation of software IPR (Copyright) & 2.21 & 1.03 & -0.79 & -15.016 & 0.001 & 1.33 to 1.53 \\
\hline violation of software IPR (Trademarks) & 3.08 & 1.19 & 0.08 & 1.327 & 0.185 & 3.04 to 3.28 \\
\hline violation of software IPR (Trade Secrets) & 3.01 & 1.08 & 0.01 & 0.236 & 0.814 & 2.92 to 3.13 \\
\hline violation of software IPR (Patent) & 2.37 & 0.99 & -0.63 & -12.506 & 0.001 & 1.64 to 1.84 \\
\hline Other issues of violation of software IPR & 3.27 & 1.12 & 0.27 & 4.694 & 0.001 \\
\hline
\end{tabular}

\section{EFFECTIVE FACTORS IN SOFTWARE PIRACY}

Two points of view can be considered for copyrights; the first point is that copyrights are incentives for creative production. The second point is that copyright is considered as a commodity for the consumer, who seeks to use it for free or at a negligible cost. Using this argument, it can be concluded that developed countries are struggling to secure the first view to have the copyright of their own works; on the other hand, in developing countries there is an attempt to reach a second view to have access to the copyright easier and at a lower cost. As the results of this study suggest, the copyright in Iran is not to be respected as well, and individuals have free access to software and some other copyrighted works free of charge. This challenge also requires growth, education and cultural developments. Also, the infrastructures ness to be corrected and punishments should be considered for the violation of copyright [9].

In this section, the effective factors in software piracy will be presented in the light of a study of previous research, which by controlling these factors, software piracy can be reduced. These factors are shown in Fig. 1. Accordingly, if in a society, these factors are controlled together at an acceptable level, software IPR will be implemented at an acceptable level.

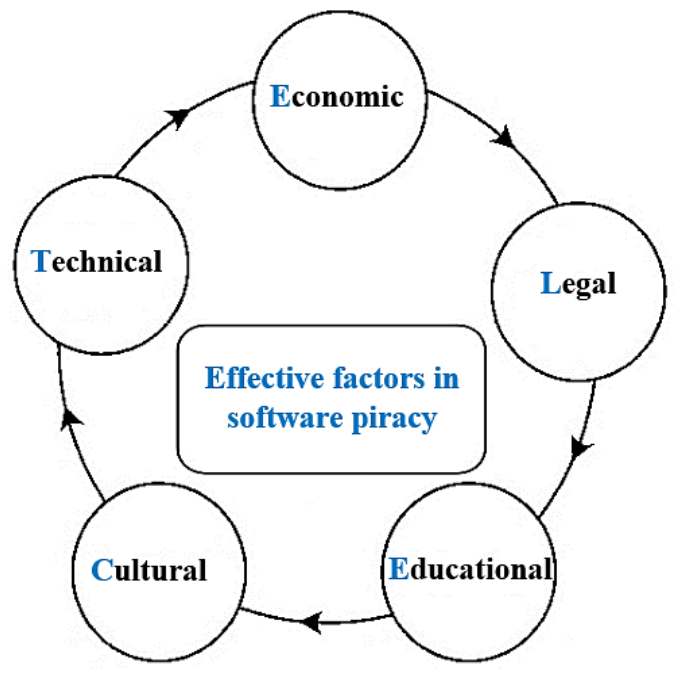

Fig. 1. Factors affecting protecting software IPR.

\section{A. Economic Dimensions}

Gross Domestic Product (GDP) is one of the factors leading to software exploitation and theft. In previous studies, the effect of software piracy on economic development has been investigated. In [14], it has been shown that levels of software piracy can increase economic development.
On the contrary, in [15], researchers found that the strict preservation of IPR would increase economic growth.

In [16], a study has been conducted in which 71 countries have been considered as population to analyses the relation between revenue release and software piracy. The results of their analysis using quintile shares showed that software piracy and software abuse exist in America, the Caribbean, East Asia, and the Pacific. It was also shown to exist in the middle and lower classes in Central Asia and Eastern Europe, and eventually in the upper classes in Western Europe and North America. Using the results, they found that in general, the inequality of negative revenue is related with software piracy.

Moreover, the amount of awareness and infrastructure required are necessary to do this. Higher Human Development Index is manifested not only in individual characteristics, but also in the infrastructure sector, for example, the infrastructure of Internet communications. Thus, as a conclusion in this regard, one can state that the higher human development index reduces the software heft or at least can strengthen this behavior.

\section{B. Legal Dimensions}

Legal cases and setting explicit rules affect software piracy. International organizations as well as governments can prevent software piracy by executing copyright contracts and increasing legal knowledge of individuals.

Unfortunately, in Iran, copyrights are not respected as they should. In this regard, the government must enforce strict rules and even take heavy fines from offenders [9].

In terms of intellectual property, the results showed that the policies of Internet Service Providers (ISPs) and, in general, the Internet and domestic policies in some countries, such as Iran, are different than other countries. As mentioned, In Iran, strict software policies are not enforced, and individuals can download software and related items freely, while these policies are strict in some countries and people cannot access these data easily. Also the effective codes of ethics as well as correct policies should also be considered [9]. In this section, the research results are consistent with other researchers' findings [17]-[21].

In [22], using a population of students of a faculty of public administration consisting of 319 students, the influence of religious factors, awareness of individuals as well as legal factors in software piracy were studied in a variety of ways and in a controlled environment. The results showed that religious factors affect people's decision on software piracy, which was the result of previous research as well. In addition, the results showed that the legal factors were not effective. Moreover, it 
was shown that informing people on the legal consequences of violating IPR could help reduce software piracy.

\section{Educational Dimensions}

According to the conducted studies and the results obtained from this study, it can be concluded that ethics in information technology can be trained to influence the individuals. Given that there is no mandatory syllabus for students in bachelors and master and $\mathrm{PhD}$ course in Iran on ethical issues in information technology, such a program seems essential to cope with the ethical challenges of IT [9]. Previous investigations also prove this claim [23]-[25].

The low level of training leads to software piracy. In [26], [27], the secondary education of people over the age of 25 years was studied. Their results showed that more training reduced software piracy.

One view is that educated people have more knowledge for software piracy, so they pay less. If we consider this, software stealing should naturally increase. However, the second view is that educated people are more aware of the nature and, ultimately, of the work, which is punishable by law.

\section{Cultural Dimensions}

Hofstede's cultural dimensions indicate the existence of levels of software piracy. Using the questionnaire and its distribution in a population, [21] was conducted on the effect of religious beliefs on software piracy and it was concluded that religious behavior decreased digital theft.

In [28], "Software piracy due to deprivation" was examined. This study showed that a reason for software piracy could be the lack of a proper financial status that would allow people to steal the software.

The rise in the price of legal software, as well as illegal sale by unauthorized agents at lower prices is one of the key factors in software piracy. This can be beneficial for non-virtual companies carrying out this.

\section{E. Technical Dimensions}

Different methods of software protection such as cryptographic mechanisms affect the level of software piracy. The type and quality of access to the Internet and its cost affect the access to the software. In [29], [30], using a population (219 professional users and 575 amateur users), software and hardware protection against unauthorized copying of the software was analyzed using a survey. The results showed that none of the protections has a significant impact on the level of theft. The only promising result was that some hardware protections are a better solution to the problem of software piracy, and at least amateur users are not able to break and abuse it. However, today, strong hardware locks are used that have reduced the possibility of software piracy. Protection and security of IP addresses also lead to higher costs for software piracy and generally, the software steal is reduced.

\section{CONCLUSIONS}

In this study, the cases related to software IRP ownership were investigated using two different populations. The results showed that the statistical community of IEEE software engineers significantly observed IPR more compared to the students. Then, a model was introduced that, if implemented in a community of this model, the violation of software IPR will reduce.

\section{FUTURE RESEARCH}

As mentioned, this research has studied to examine the level of familiarity with IPR of software and its observance, and how much IPR is tangible and familiar to population has been analyzed among an academic setting. Further research can consider on non-academic statistical samples.

\section{REFERENCES}

[1] R.K. Goel and M.A. Nelson, "Determinants of software piracy: Economics, institutions, and technology" The Journal of Technology Transfer, Vol. 34, No. 6, 2009, 637-658.

[2] I. P. Png, On the reliability of software piracy statistics. Electronic Commerce Research and Applications, Vol. 9, No. 5, 2010, 365-373.

[3] J. Choi, Y. Han, S.J. Cho, H. Yoo, J. Woo, M. Park, ... and L. Chung, “A static birthmark for MS windows applications using import address table". In Innovative Mobile and Internet Services in Ubiquitous Computing (IMIS), Seventh International Conference on 2013, 129-134.

[4] R. Thomas, "Debugging software patents: increasing innovation and reducing uncertainty in the judicial reform of software patent law", 191241.

[5] D. Suh and J. Hwang, "An analysis of the effect of software intellectual property rights on the performance of software firms in South Korea", Vol. 30, No. 5, 2010, 376-385.

[6] B. Hall and M. MacGarvie, "The private value of software patents", Vol. 39, No. 7, 2006, 994-1009.

[7] R. Mann and T. Sager, "Patents, venture capital, and software start-ups", Research Policy Vol. 36, No. 2, 2007, 193-208.

[8] A. Hedayatpanah, "Fuzzy approach to Likert Spectrum in Classified levels in Surveying researches" Journal of Mathematics and Computer Science, Vol. 2, No. 2, 2011, 394-401.

[9] E. Sargolzaei and M. Nikbakht, "The Ethical and Social Issues of Information Technology: A Case Study" International Journal of Advanced Computer Science and Applications(IJACSA), 8(10), 2017.

[10] J. Santos and A. Reynaldo, “Cronbach's alpha: A tool for assessing the reliability of scales", Journal of extension,Vol. 37, No. 2, 1999, 1-5.

[11] S. Tobias and J.E. Carlson, "Brief report: Bartlett's test of sphericity and chance findings in factor analysis" Multivariate Behavioral Research,Vol. 4, No. 3, 1969, 375-377.

[12] Y. Pal, "A Theoretical study of Some Factor Analysis Problems and Pal, Y. and Bagai, OP A Common Factor Better Reliability Approach to Determine the Number" 1987.

[13] C.A. Boneau, "The effects of violations of assumptions underlying the $t$ test" Psychological bulletin,Vol. 57, No. 1, 1960, 49.

[14] A.R. Andrés and R.K. Goel, "Does software piracy affect economic growth? Evidence across countries. J. Policy Model” ,Vol. 34, No. 2, 2012, 284-295.

[15] R. Falvey, N. Foster and D. Greenaway, "Intellectual property rights and economic growth" Review of Development Economics. ,Vol. 10, No. 4, 2006, 700-719.

[16] J.A. Fischer and A.R. Andrés, "Is Software Piracy a Middle Class Crime? Investigating the Inequality-Piracy Channel",2005.

[17] A. Mertha, "The politics of piracy: Intellectual property in contemporary China", Cornell University Press, 2005.

[18] L. Stein and N. Sinha, "New global media and communication policy: the role of the state in the twenty-first century", Handbook of new media: Social shaping and consequences of ICTs, 2002, 410-31.

[19] R.A. Spinello and H.T. Tavani, "Intellectual Property Rights: From Theory to" Intellectual property rights in a networked world: Theory and practice, 2005, 1.

[20] K. Kimppa, "Intellectual Property Rights in Software-Justifiable from a Liberalist Position?" Intellectual property rights in a networked world: Theory and practice,2005, 67. 
[21] B.C. Stahl, "The impact of open source development on the social construction of intellectual property" Free/open source software development, 2005, 259-272.

[22] S. Al-Rafee and K. Rouibah, "The fight against digital piracy: an experiment. Telematics Inform", Vol. 27, No. 3, 2010, 283-292.

[23] D.K. Peterson, "Deviant workplace behavior and the organization's ethical climate", Journal of business and psychology,Vol. 17, No. 1, 2002,47-61

[24] I. Phau and G. Kea, "Attitudes of university students toward business ethics: a cross-national investigation of Australia, Singapore and Hong Kong”, Journal of Business Ethics,Vol. 72, No. 1, 2007, 61-75.

[25] C. Kum-Lung and L. Teck-Chai, "Attitude towards business ethics: examining the influence of religiosity, gender and education levels", International Journal of Marketing Studies,Vol. 2, No. 1, 2010,: 225
[26] A.R. Andrés, "Software piracy and income inequality", Vol. 13, No. 2 , 2006, 101-105.

[27] R.J. Barro and J.W. Lee, "A new data set of educational attainment in the world, 1950-2010", Vol. 104, 2013, 184-198.

[28] G.J. Hofstede, "Cultures and Organizations: Software of the Mind" third", Administrative Science Quarterly, 38, 132-134.

[29] A. Prasad and V. Mahajan, "How many pirates should a software firm tolerate? an analysis of piracy protection on the diffusion of software", International Journal of Research in Marketing, Vol. 20, No. 4, 2003, 337-353.

[30] B. Anckaert, B.D. Sutter and K.D. Bosschere,"Software piracy prevention through diversity", In Proceedings of the 4th ACM workshop on Digital rights management, 2004, 63-71, ACM. 